\title{
Pattern of Pediatric Dermatoses in a Tertiary Care Referral Centre in Andhra Pradesh
}

\author{
Dr. T. Vani ${ }^{1}$, Dr. Ch. Ramamohan ${ }^{2}$, Dr. S. Nageswaramma ${ }^{3}$, Dr. S. Madhuri ${ }^{4}$ \\ ${ }^{1,2,3,4}$ Department Of D.V.L, Guntur medical college, Guntur, Andhra Pradesh, India
}

\begin{abstract}
Background: Skin diseases are one of the common health problems in the paediatric age group. The morbidity caused by certain dermatoses in this age group is associated with significant psychosocial impact. Cutaneous infections are commonly encountered in children of school going age. The predisposing factors for this common occurrence are low socioeconomic status, climatic conditions, poor dietary intake and lack of hygiene. Aim: The aim of this study is to evaluate the magnitude of various skin diseases and their pattern of occurrence among children up to 14 years of age. Methods: Consecutive 2075 children aged up to 14 years, attending the tertiary care hospital were the subjects of this study. A detailed history and cutaneous examination were done. Thorough general and systemic examination followed by relevant investigations was carried out as and when necessary. The findings were recorded in a proforma for analysis and interpretation of the data. Results: Out of 2075 children, majority 1117(53.83\%) are having various infections and infestations followed by eczemas 297(14.31\%). Conclusion: In our study the major cause of morbidity in children was infections and infestations. Among infections and infestations scabies 541(26.07\%) was the most common entity followed by bacterial 295(14.21\%), fungal 210(10.12\%) and viral 71(3.34\%) infections.
\end{abstract}

Keywords: Paediatric dermatoses, infections, infestations, eczemas, scabies

\section{Introduction}

Skin diseases form a major cause of morbidity in children. An overall view of major causes of paediatric dermatoses in the community is more than essential for a dermatologist or paediatrician. They are important health problem affecting children in both developing and industrialized countries with variable prevalence and pattern. There are many risk factors for development of skin disease in the paediatric population; ecological and environmental including racial and genetic factors, nutritional status, climatic exposure, external environment, traditional taboos, and socioeconomic status; personal hygiene, large family size and over-crowding. Neonatal dermatoses are associated with genetic factors. Paediatric dermatoses require a separate view from adult dermatoses as there are important differences in clinical presentation, management and prognosis. They can be transitory or chronic and recurrent, and although they are rarely lethal, they may be associated with significant morbidity and psychological impact as well as an implication in their development.

\section{Materials and Methods}

A prospective observational study was conducted in Government General Hospital, Guntur ,Andhra Pradesh for a period of one year from August 2014 to July 2015. A total of 2075 children attending our DVL Department OPD were included in the study.

Inclusion criteria

Children below 14 years are included in the study

Both males and females included
Exclusion criteria:

Children above 14 years are excluded from the study

\section{Results}

Males outnumbered females slightly in the ratio 1.1:1

Various common causes included

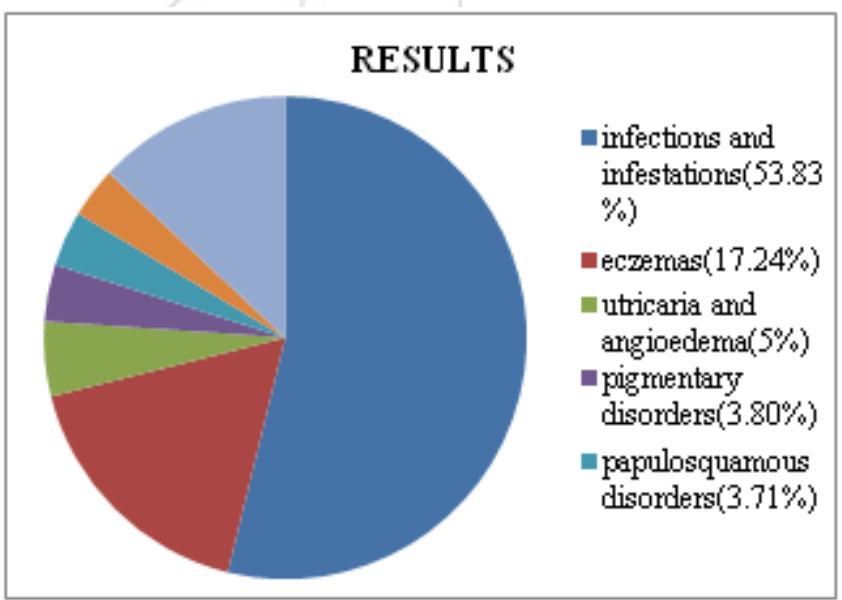

Other causes include

\begin{tabular}{|c|c|}
\hline Acne & $1.68 \%$ \\
\hline Hair disorders & $1.49 \%$ \\
\hline PMLE & $1.10 \%$ \\
\hline Drug reactions & $0.62 \%$ \\
\hline Vesiculobullous & $0.09 \%$ \\
\hline Miscellaneous & $4.53 \%$ \\
\hline
\end{tabular}




\section{International Journal of Science and Research (IJSR) \\ ISSN (Online): 2319-7064}

Index Copernicus Value (2013): 6.14 | Impact Factor (2015): 6.391

Age distribution of disorders

\begin{tabular}{|c|c|c|c|c|c|c|}
\hline Dermatoses & & Male & & & Female & \\
\hline & $0-5$ years & $5-10$ years & 10-14 years & $0-5$ years & $5-10$ years & $10-14$ years \\
\hline \multicolumn{7}{|l|}{ Infections } \\
\hline Bacterial & 94 & 44 & 19 & 77 & 35 & 23 \\
\hline Viral & 23 & 11 & 4 & 12 & 10 & 11 \\
\hline Fungal & 21 & 21 & 43 & 31 & 28 & 66 \\
\hline Parasitic & 123 & 90 & 14 & 130 & 82 & 77 \\
\hline Eczemas & 46 & 53 & 27 & 50 & 55 & 59 \\
\hline Urticaria & 27 & 19 & 17 & 12 & 16 & 17 \\
\hline \multicolumn{7}{|l|}{ Pigmentary disorders } \\
\hline Hypopigmentary & 4 & 14 & 13 & 7 & 11 & 11 \\
\hline Hyperpigmentary & 3 & 3 & 2 & 1 & 5 & 4 \\
\hline \multicolumn{7}{|l|}{ Papulosquamous } \\
\hline Psoriasis & & 14 & 5 & 5 & 10 & 4 \\
\hline Pityriasis rosea & 2 & 5 & 5 & 3 & 11 & 4 \\
\hline Lichen planus & & 5 & 4 & & & 4 \\
\hline Keratinization disorders & 5 & 17 & 9 & 6 & 14 & 9 \\
\hline Acne & 1 & 2 & 9 & 1 & 2 & 20 \\
\hline Hair disorders & 2 & 2 & 3 & 3 & 9 & 8 \\
\hline PMLE & 1 & 1 & 8 & 4 & 1 & 7 \\
\hline Drug reactions & 4 & 1 & 2 & 1 & 3 & 2 \\
\hline Vesiculobullous & 1. & 1 & 18 & $\mathrm{O}=$ & & 1 \\
\hline Genodermatoses & 5 & 3 & 1 & 1 & 4 & 0 \\
\hline Miscellaneous & 20 & 9 & 19 & 17 & 15 & 13 \\
\hline
\end{tabular}

\section{Discussion}

Infections and infestations were the most common paediatric dermatoses seen in our study. This is consistent with other studies from developing countries but differ from developed countries where skin infections are rare.

Infections and infestations:

Among infections scabies was the most common infestation observed in our study, followed by bacterial infections, fungal and viral infections in that order. Sayal et al., reported fungal infections to be more common, while viral infections out-numbered bacterial and fungal infections in a study by Wenk and Itin and Gul et al., ${ }^{2}$ The variation among infective dermatoses can possibly be attributed to the region of study, prevalent environmental factors, type of population studied, and hygiene and nutritional status.

The results of our study revealed that scabies, a skin disease associated with poverty, overcrowding, and sometimes water scarcity, is prevalent among school-aged children. More than half of them were in the early school-aged years. The male to female ratio from the study is almost equal with marginal increase in favour of females .Pediculosis is second most common infestation. It is 4 times more common in females than in our study.

Among bacterial infections impetigo was the most common infection observed followed by secondary pyoderma, folliculitis.impetigo was most common bacterial infection in most studies ${ }^{3,4,6,7}$. Most of the cases were pencillin sensitive. Most common fungal infection observed was dermatophyte infections followed by candidiasis. Tinea capitis was the most common fungal infection,followed by tinea corporis and faciei. This is in accordance with other studies ${ }^{8,9}$.Most common viral infection was verrucca followed by molluscum contagiosum, varicella and herpes zoster.This is in accordance with study conducted by Nanda at al.

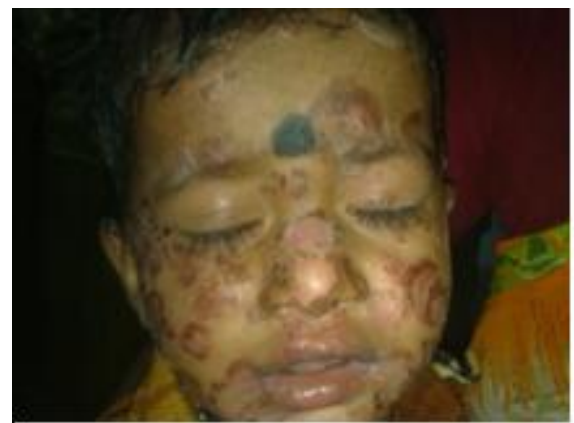

Impetigo contagiosa

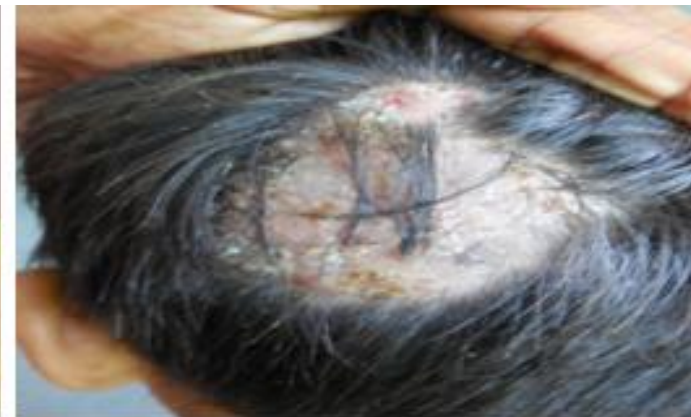

Kerion 


\section{International Journal of Science and Research (IJSR) \\ ISSN (Online): 2319-7064}

Index Copernicus Value (2013): 6.14 | Impact Factor (2015): 6.391

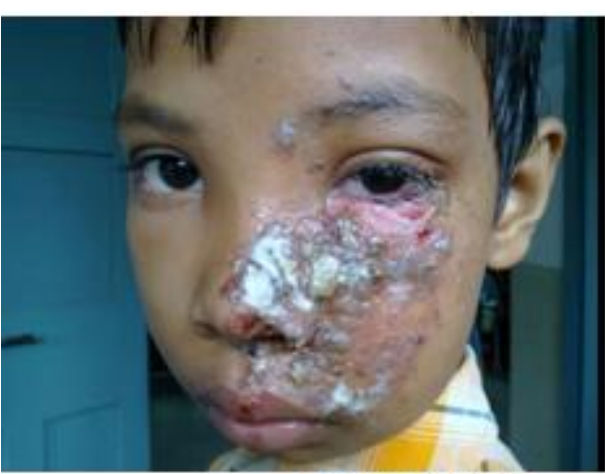

Herpes Zoster

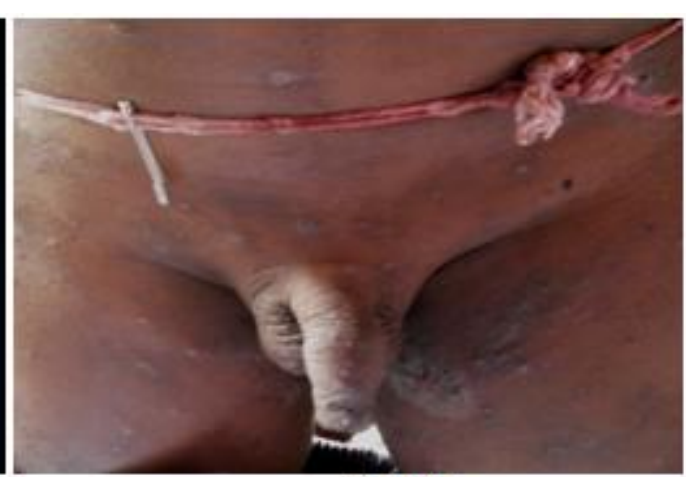

Scabies

\section{ECZEMAS:}

Different forms of endogenous or exogenous eczemas were seen in this study. Eczema was the second major presentations among our paediatric patients. In our study, we diagnosed 173 patients with atopic dermatitis (8.32\%), it was the most common diagnosed eczema. In most studies done in developed countries, atopic dermatitis was the most frequent diagnosis in children ${ }^{10}$. This relatively high frequency of atopic dermatitis in our children may be related to the dietary habits and environmental factors including allergens in addition to the role of the genetic factor. Although atopic dermatitis was seen in all age groups except neonates, its frequency was statistically significant more in infancy as many atopic patients experience improvement with age. Infantile seborrhoeic dermatitis is a common inflammatory disease with spontaneous improvement with age. Contact dermatitis was the third common eczema encountered.

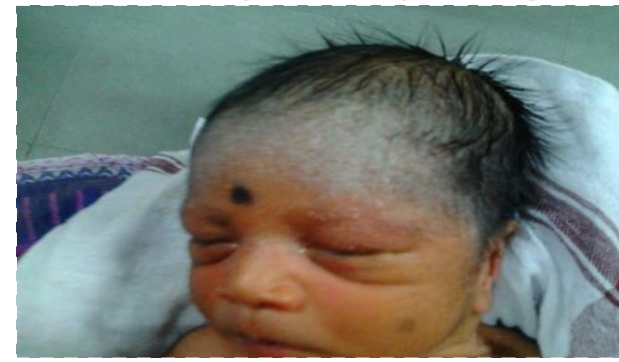

Infantile Seborrhoreic Dermatitis

Utricaria $(5 \%)$ is one of the common complaint in our study.it is more common between ages 6-14.equal incidence in males and females.post inflammatory hypopigmentation was the most common pigmentary disorder followed by vitiligo.psoriasis was the most common papulosquamous disorder followed by pityriasis rosea and lichen planus.acne vulgaris is more common in females it was the most common diagnosis in some Turkish studies.,this may be due to difference in age structure of study.

Vesiculobullous disorder reported was chronic bullous dermatoses of childhood.various genodermatoses reported in our study were lamellar icthyosis, colloidon baby,epidermolysis bullosa simplex and dystrophica,tuberous sclerosis and neurofibromatoses. Morphological types of drug reactions encountered were morbilliform rash,fixed drug eruption,toxic epidermal necrolysis. Most common drug implicated was carbamazepine.

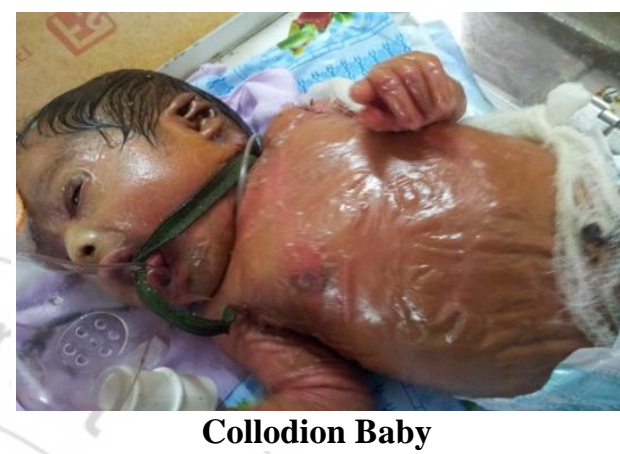

The prevalence of certain dermatoses is influenced by seasonal variations ${ }^{11}$.acne patients were presented more in winter and autumn in our study.atopic dermatitis and seborrhic dermatitis was more common in winters.

\section{Conclusion}

Our study shows various features of pediatric dermatoses in a developing country, such as high frequency of infectious diseases. These infections are controllable and preventable if there are stratagies to target infections in child health programs. The need for specialized pediatric dermatology clinics in the general hospital should be emphasized.

\section{References}

[1] Sayal SK, Bal AS, Gupta CM. Pattern of skin diseases in pediatric age group and adolescents. Indian $\mathrm{J}$ Dermatol Venereol Leprol 1998;64:117-9.

[2] Gul U, Cakmak SK, Gonul M, Kilic A, Bilgili S. Pediatric skin disorders encountered in a dermatology outpatient clinic in Turkey. Pediatr Dermatol 2008;25:277-8.

[3] Hayden GF. Skin diseases encountered in a pediatric clinic. Am J Dis Child 1985;139:36-8.

[4] Javed M, Jairamani C. Pediatric dermatology: An audit at Hamdard University Hospital, Karachi. J Pak Assoc Dermatol 2006;16:93-6.

[5] Mitra M, Mitra C, Gangopadhyay DN. Effect of environment on pediatric dermatoses. Indian J Dermatol 2005;50:64-7.

[6] Koley SK, Sen MK, Sengupta SN. Incidence of skin diseases in children in the district of Bankura. Indian J Pediatr 1975;42:106-9

[7] Nanda A, Hasawi FA, Alsaleh QA. A prospective survey of pediatric dermatology clinic patients in 


\section{International Journal of Science and Research (IJSR) \\ ISSN (Online): 2319-7064}

Index Copernicus Value (2013): 6.14 | Impact Factor (2015): 6.391

Kuwait: An analysis of 10,000 cases. Pediatr Dermatol 1999;16:6-11.

[8] Ghosh SK, Saha DK, Roy AK. A clinico-aetiological study of dermatoses in paediatric age group. Indian $\mathbf{J}$ Dermatol 1995;40:29-31.

[9] K, Mahajan S, Sarkar R, Mendiratta V, Bhushan P, Koranne RV, et al. The spectrum of skin disease among Indian children. Pediatr Dermatol 2009;26:6-13.

[10] Child FJ,Fuller LC,Higgins EM,Du Vivier AW.A study of spectrum of skin disease occurring in black population in south-east London. $\mathrm{Br} \mathrm{J}$ Dermatol 1999; $141: 512-7$

[11]Balai M, Khare AK, Gupta LK, Mittal A,Kuldeep CM. Pattern of pediatric dermatoses in a tertiary care centre of South West Rajasthan. Indian J Dermatol 2012;57:275-8.

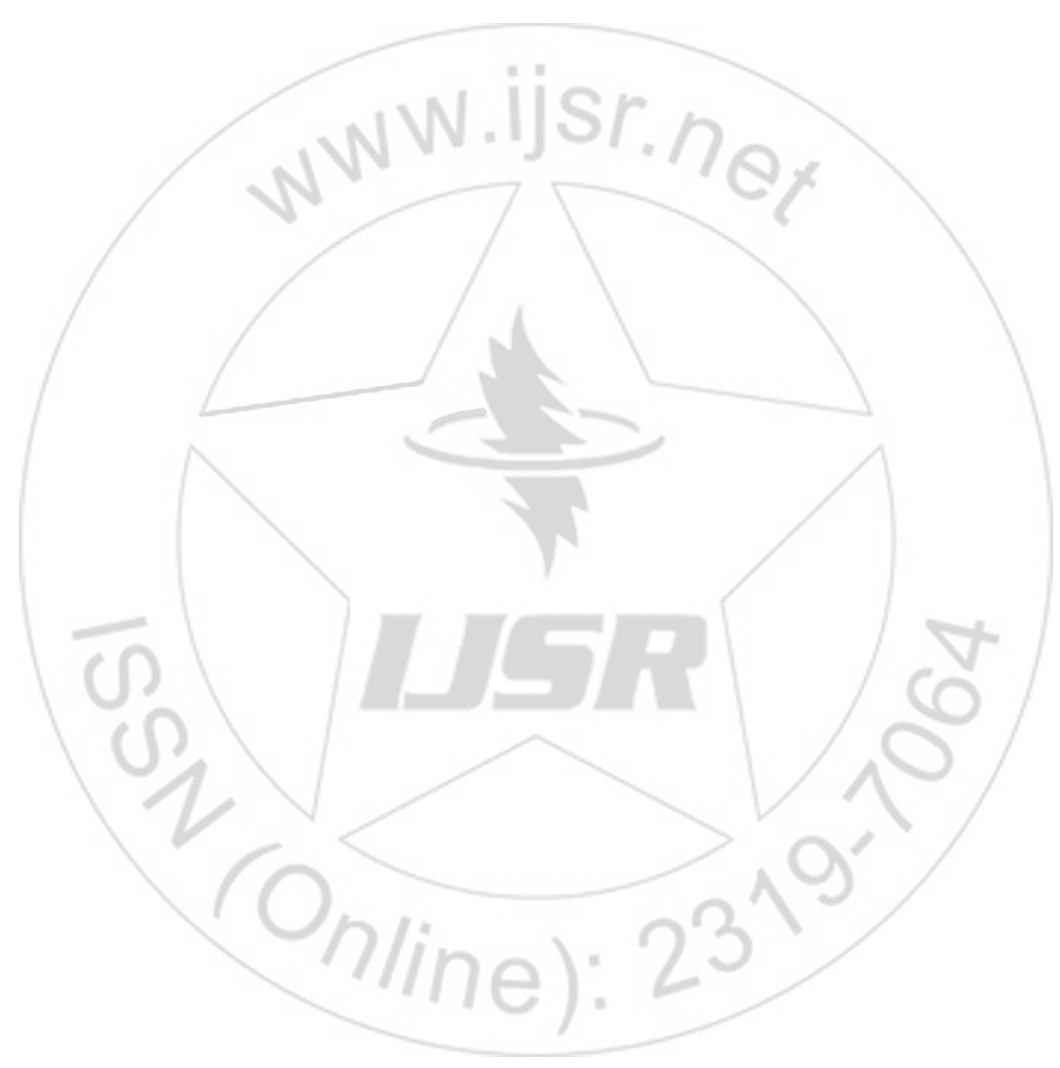

Volume 5 Issue 5, May 2016 